\title{
Knowledge Management in Nigerian Universities: A Conceptual Model
}

\author{
Adebowale Ojo \\ School of Management, IT \& Governance \\ University of KwaZulu-Natal, Westville, Durban, South Africa
}

ojoa@ukzn.ac.za

\begin{abstract}
Universities have traditionally been leaders in the field of knowledge production, research, and societal development. They are expected to be drivers of innovation, thereby contributing to the development of a learning society. The array of challenges facing universities in Nigeria and other developing countries forces one to question their levels of innovation. While knowledge management has been identified as a strategy for driving innovative processes in business organizations, there is a paucity of literature on its application in Nigerian universities. This paper, therefore, proposes a conceptual model which Nigerian universities could adopt, in order to drive innovation and performance. As the paper is conceptual in nature, a literature survey was conducted to examine the concept of knowledge management and its application in higher education institutions. Findings from the literature informed the development of a conceptual model describing ways in which universities can adopt knowledge management practices and strategies in order to drive innovation and improve performance. The conceptual model proposed in this paper could serve as a basis for empirical investigations on knowledge management processes in universities. The paper concludes that, while knowledge management has the potential for improving performance within universities, the proposed model must be subjected to empirical validation for further amendments and improvements.
\end{abstract}

Keywords: knowledge management, higher education, innovation, university, Nigeria

\section{Introduction}

Universities are the intellectual center of knowledge production and research. They are responsible for education, research, and knowledge transfer to society, hence, contributing to national development. The potential of universities to transform society economically, politically, socially, and culturally has been well documented in the literature (Brennan, King, \& Lebeau, 2004). In the emerging knowledge society, universities are the expected drivers of innovation, thereby con-

(CC BY-NC 4.0) This article is licensed to you under a Creative Commons AttributionNonCommercial 4.0 International License. When you copy and redistribute this paper in full or in part, you need to provide proper attribution to it to ensure that others can later locate this work (and to ensure that others do not accuse you of plagiarism). You may (and we encourage you to) adapt, remix, transform, and build upon the material for any non-commercial purposes. This license does not permit you to use this material for commercial purposes. tributing to the development of a learning society. It may, therefore, be correct to posit that a nation's development is dependent on the ability of its universities to produce new knowledge, new technology, and quality graduates. In contributing to national development, universities have a role in preparing graduates, not simply for the present time, but also for the emerging society which is characterized by technological advancements (Ramakrishnan \& Yasin, 2012). Universities may, therefore, be seen as 
the key drivers in the emerging knowledge economy who are thus required to innovate as well as collaborate with industries for research and development purposes. In the same vein, Chen, Chen, and Padró (2015) opined that higher education institutions should be able to meet the needs of students and society while attending to the well-being of the institution itself.

In the Nigerian context, the National Universities Commission (NUC) serves as the regulatory body for all universities in the country. The NUC is charged with approving all academic programs within the universities: approving the establishment of all degree-awarding institutions, ensuring quality assurance of all academic programs, and serving as a channel for all external support to the universities (NUC, 2016a). Historically, as documented by Ololube, Dudafa, Uriah, and Agbor (2013), five federal government universities were initially established in Nigeria: the University College, Ibadan, in 1948, which is now known as the University of Ibadan; the University of Nigeria, Nsukka (1960); Ahmadu Bello University, Zaria (1962); the University of Ife, Ile-Ife (1962), which is now known as Obafemi Awolowo University; and the University of Lagos, Lagos (1962). These universities were reported to have been established on the basis of the government's recognition of the role of education in attaining national economic expansion, individuals' social emancipation, as well as producing the knowledgeable and competent workforce needed for national development (Ololube et al., 2013). Presently, in Nigeria, there are 40 federal government-run universities, 42 state-owned universities, and 61 private universities, all approved by the NUC (NUC, 2016b).

Higher education institutions all over the world are grappling with a number of challenges, making it difficult to achieve their set objectives while simultaneously maintaining their historical role of contributing effectively to society. Some of these challenges, as highlighted by Chen et al. (2015), include fiscal constraints and increased calls for accountability, growing demand for enrollment, and challenges from evolving technologies. These challenges are also prominent within the Nigerian higher education context. For instance, Akinyemi and Bassey (2012) note that, despite the increase in the number of universities, there remains a wide gap between the demand and supply of university education: that is, there is high demand for admission places; however, the enrollment figures are low. Ezepue (2015) cited some of the challenges facing higher education in Nigeria as the following: lack of skills-focused critical education; a grossly inadequate curriculum producing graduates not ready for employment; graduates without study and criticalthinking skills; graduates with low self-confidence, low self-esteem, and low self-efficacy, among other impediments. In the same vein, Famurewa (2014), in an analysis of funding of higher education in Nigeria, concluded that inadequate funding is the bane of tertiary education in Nigeria. Furthermore, the challenges facing higher education institutions in Nigeria are those of creating competitive institutions in a globalized world, providing access without compromising quality, promoting competition among providers, attracting and retaining talent, and ameliorating inadequate human-resource capacity. Further trials are poor input from the lower systems, inadequate funding, and reluctance of beneficiaries to share in the cost of providing quality education. Further obstacles include internal corruption; inefficient bureaucracy; and political interference (Akinrinade, 2013; Ololube et al., 2013).

There are also challenges relating to the use of information and communication technology (ICT) tools for teaching and learning. Echeng, Usoro, and Majewski (2013), in a study of the acceptance of Web 2.0 technologies in some Nigerian universities, report low levels of familiarity and utilization on the part of lecturers and students of some of the technologies that can be used to facilitate teaching and learning. These burdens, which affect both government and privatelyowned universities, compromise their quality and their performance. An indication of these challenges is further revealed in the Times Higher Education World University Rankings, which is a global university performance table that judges world class universities across all of their core missions - teaching, research, knowledge transfer, and international outlook (Times Higher Edu- 
cation, 2016). A careful examination of these rankings for 2016/2017 reveals that no Nigerian university ranks among the top 500 universities in the world or in the top 100 universities in emerging economies (Times Higher Education, 2016).

The aforementioned challenges, therefore, suggest that, for universities who see themselves in the knowledge business, the need for innovation has never before been greater. This is particularly true considering the advancements in technology and the transformation of the information society into a knowledge society. It becomes vital, therefore, for organizations intending to survive in this age to innovate, learn, and adapt to change - as this is not so different from the "publish or perish' syndrome pervasive in academic circles (Rowley, 2000). Innovation is also a knowledgemanagement process, depending on the way organizations are able to use their knowledge to create something new (Plessis, 2007). According to White and Glickman (2007), innovation in institutions of higher learning affords the flexibility with which universities can adapt to the constantly changing environment. In addition, innovation provides tools to cope with increasing accountability demands and cost pressures, thus enabling greater efficiency in making the best use of available resources. Universities, as knowledge-based institutions, are expected to manage knowledge for sustainable competitive advantage, growth, and innovation (Ohiorenoya \& Eboreime, 2014). A key tool for achieving this is the ability to identify, value, create, and evolve knowledge assets (Rowley, 2000). Lyman (as cited in Metcalfe, 2006) cites knowledge management as a technique that will increase institutional innovation in the higher education scene. It therefore becomes imperative for higher educational institutions to adopt knowledge management strategies for innovation's sake, thereby positioning themselves to surmount the challenges they face in this age.

Researchers identify knowledge management initiatives as tools for driving innovative processes and maintaining competitiveness within business organizations (Bhatt, 2001; Carneiro, 2000). However, the role of knowledge management techniques or strategies to improve performance in Nigerian universities is not clear. Also, the knowledge management processes in Nigerian universities, if existing, have not been documented in the literature. This suggests that there is no framework for knowledge management application in Nigerian institutions of higher learning. A study conducted by Krubu and Krub (2011) noted that, while faculty members in Nigerian universities have awareness of knowledge management practices, there are no strategies or policies in place to drive implementation. Therefore, in the face of the diverse challenges confronting Nigerian universities, this paper proposes a conceptual model for knowledge management application. While knowledge management strategies may not be able to solve all of the challenges in the Nigerian university system, it is hoped that an application of the proposed model will help to drive innovation, thereby enhancing quality and performance.

This is a conceptual paper, hence it draws inferences from a review of existing literature. The subsequent sections of this paper focus on the concept of knowledge management by examining various definitions of knowledge management. Thereafter, the researcher appraises studies that have pondered the applicability of knowledge management within universities. Consequently, the major objective of this paper, which is to propose a conceptual model for knowledge management application in Nigerian universities, is established.

\section{Overview of Knowledge Management}

The parable of the three blind men and the elephant - a situation in which each man touched and described the various body parts of the elephant according to his perception - exemplifies the concept of knowledge management. This similarity arises because of the various concepts and definitions suggested by several authors of diverse academic backgrounds. The concept is well captured by Abell and Oxbrow (2006), who liken knowledge management to beauty - found in the eye of the beholder. In fact, while some scholarly brows have been raised concerning the 
seemingly faddish characteristics of knowledge management, certain other scholars have debunked this concern (Cranfield \& Taylor, 2008; Rowley, 2000). Knowledge management is now accepted as being a strategy which organizations must adopt to survive in this era of knowledge economy.

Knowledge management, as defined by Dalkir (2009), is the "deliberate and systematic coordination of an organization's people, technology, processes, and organizational structure to add value through reuse and innovation" (p. 3132). Knowledge management is achieved through creating, sharing, and applying knowledge, as well as through feeding best practices and the valuable lessons learned into corporate memory. This is in order to foster continued organizational learning. According to Kidwell, Vander Linde, and Johnson (2000), knowledge management is the process of transforming information and intellectual assets into enduring value and of connecting people with the knowledge that they need to take action when they need it. It is also the process of identifying, growing, and effectively applying an organization's existing knowledge in order to achieve the organization's goals, while creating an organizational culture that permits further knowledge creation (Sunassee \& Sewry, 2002).

While a plethora of definitions exist for what constitutes knowledge management, it is evident that most of these point out that knowledge management involves leveraging knowledge toward the attainment of organizational goals and objectives. Also, it encompasses managing knowledge assets, whether resident in individuals, in knowledge repositories, or as the process of knowledge generation and application. Ruggles and Holtshouse (1999) identify the following key attributes of knowledge management: generating new knowledge; accessing valuable knowledge from outside sources; using accessible knowledge in decision-making; embedding knowledge in processes, products, and/or services; representing knowledge in documents, databases, and software; facilitating knowledge growth through culture and incentives; transferring existing knowledge to other parts of the organization; and measuring the value of knowledge assets and/or impact of knowledge management.

Rastogi (2000) posits that, for meeting the knowledge management requirements, organizations must plan and implement the following processes: identification of the knowledge required for a competitively effective implementation of enterprise strategy; mapping the existing and available knowledge, including expertise and skills; capturing the existing knowledge through its formalized representation; acquiring necessary knowledge and information, including know-how; storing the existing, acquired, and created knowledge in properly indexed and interlinked knowledge repositories; sharing knowledge through its automatic access and distribution to users on the basis of their needs and interests; applying actions in support of decisions, problem-solving, providing job aids and training; and creating, generating, or discovering new knowledge through research and development, experimentation, lessons learned, creative thinking, and innovation.

A fundamental description of knowledge management via a knowledge conversion lens is provided by Nonaka (1994), in which a SECI (socialization, externalization, combination, internalization) model is proposed. Two types of knowledge are described: tacit knowledge and explicit knowledge. Tacit knowledge is highly personal, hard to formalize, and difficult to communicate to others. It is deeply rooted in action and in an individual's commitment to a specific content. Explicit knowledge is formal and systematic knowledge that can easily be captured, accessed, shared and transmitted in formal language. Nonaka (1994) submits that knowledge creation occurs as a result of the interaction between tacit and explicit knowledge. Socialization is the first phase of the SECI model and is the conversion of an existing tacit to a new tacit knowledge, and usually entails developing new knowledge through shared personal experiences. Externalization is the conversion of tacit knowledge into explicit knowledge. Combination is the conversion of an existing explicit to a new explicit knowledge, that is, the blending of explicit knowledge in vari- 
ous sources to enhance the existing knowledge pool. The final phase is internalization, which is the conversion of explicit knowledge into tacit knowledge.

Bukowitz and Williams (2000) describe a knowledge management process framework that outlines the way in which organizations generate, maintain, and deploy a strategically correct stock of knowledge to create value. The processes of the framework are seeking out information needed in order to make decisions, solve problems, or innovate; combining information in new and interesting ways in order to foster organizational innovation; establishing a formal system of learning from experiences as a means of creating competitive advantage; motivating employees to post what they have learned to the communal knowledge base; developing metrics to demonstrate that the institution is growing its knowledge base and profiting by its investments; and ensuring that the organization's future intellectual capital will keep the organization viable and competitive.

Likewise, various scholars have developed a number of models to outline the knowledgemanagement process. It is important to examine some of these models for better understanding of the elements constituting the knowledge management process, one of which, that is of importance to this study, is Wiig's 1993 model.

Wiig (1993) posits three conditions that must be present for any organization to conduct its business successfully: business (products/services) and customers; resources (people, capital, and facilities); and the ability to act. At the center of these conditions is knowledge, which observers see as the principal force that determines and drives the ability to act intelligently. The four major phases of the model outlined by Wiig are build, hold, pool, and apply knowledge. In the first phase of the model, build, the author highlights major functions and activities such as obtaining, analyzing, reconstructing, codifying, and organizing knowledge by knowledge workers, in order to make products and provide services. The second phase, hold, involves remembering, accumulating, and embedding knowledge in repositories, and archiving knowledge. The third phase, pool, consists of coordinating, assembling, accessing, and retrieving knowledge at the collective level of the organization. Finally, the fourth phase, apply, infers using knowledge to perform tasks in order to generate benefits.

An integrated knowledge management model that is also of interest to this paper is that of Evans, Dalkir, and Bidian (2014). The authors, after a review of various prominently used models in the knowledge management discipline, propose an integrated model with seven phases: identify, store, share, use, learn, improve, and create. The first phase, identify, involves eliciting codified and encapsulated knowledge assets. It also involves analyzing and assessing the assets based on specific organizational rules, cultures, and evaluation criteria. This phase is interrelated with the store phase, as well as leading to the create phase. The create phase is concerned with creating new knowledge which may be triggered by a knowledge request, especially if none is found through searching at the identify stage. Some organizational initiatives that may assist in the creation of knowledge are expert interviewing, prototyping, workflow analysis, and competence and process mapping. The store phase is the storage of valuable knowledge in the organizational memory. This is based on the analysis and assessment carried out in the identify and create phases. The share phase is the knowledge-sharing phase. Here, knowledge assets retrieved from the organizational memory are disseminated or communicated, both internally and externally. The use phase is concerned with activating knowledge assets. This phase entails that values embedded in knowledge assets are extracted and applied throughout the organization to solve problems, make decisions, improve efficiency, or promote innovative thinking. The authors emphasize here that, unless this phase is accomplished successfully, all of the knowledge management efforts have been in vain. The learn phase involves deconstructing knowledge blocks, integrating, connecting, combining, and internalizing knowledge. This ensures that knowledge assets that have been shared and used will also provide the foundation for creating and refining existing knowledge assets. At this stage, if knowledge assets are found to be valuable, the organization 
may proceed to the improve phase; otherwise, the process is returned to the identify and/or create phase. The final phase, improve, is the decision point for knowledge assets to be archived, retired, or transferred outside the organization for further use.

The models reviewed above indicate that knowledge must pass through certain stages before it can help organizations derive benefits from its application. It is worth noting that developers of the above-mentioned frameworks have business organizations in mind, not necessarily higher education organizations. Also, models that focus on higher education institutions seem scarce, thereby calling for an example which addresses the peculiarities of higher education institutions.

\section{Knowledge Management in Higher Education}

Having examined the concept of knowledge management, it is expedient to consider its application in higher education. While the corporate business sector has widely explored knowledge management, higher educational institutions have yet to follow suit. In fact, studies have noted that universities are lagging behind in implementing knowledge management strategies, perhaps because of an academic culture of knowledge hoarding (Brewer \& Brewer, 2010; Marouf \& Agarwal, 2016). Also, the bureaucratic system inherent in academic settings, and sometimes the lack of social interaction which limits social networks, as well as an individualistic knowledge sharing culture, could be responsible for the slow uptake of knowledge management initiatives in universities (Fullwood, Rowley, \& Delbridge, 2013; Omerzel, Biloslavo, \& Trnavčevič, 2011). It could also be because of the traditionally hierarchical nature with silo-like functions of universities, making cross-functional initiatives, like knowledge management, difficult to implement (Petrides \& Nguyen, 2006). Petrides and Nguyen (2006) further highlight some of the challenges to implementing knowledge management in higher education institutions: disintegrated information systems with inconsistent priorities around data collection resulting in inaccessible or unreliable data; cultural issues linked with information hoarding; and disincentives for sharing and cross-functional cooperation.

However, considering that universities already have significant levels of knowledge management activities, it is only to be expected that they would be conscious of this and would set a foundation for further development, rather than invent a new paradigm. Universities should, therefore, consciously and explicitly manage the knowledge management processes inherent in them (Rowley, 2000). According to Adhikari (2010), the radical changes pervading the academic environment require concerted efforts at knowledge management implementation in order to derive 'bottom-line benefits'. It is universities that meet the knowledge needs of students and society that achieve such bottom-line benefits. Adhikari (2010) further defined knowledge management in the context of academic institutions as "the organized and systematic process of generating and disseminating information, and selecting, distilling, and deploying explicit and tacit knowledge to create unique value that can be used to strengthen teaching-learning environment" (p. 99).

Yeh (2011) indicates two types of knowledge involved in higher education settings: academic knowledge and organizational knowledge. The primary purpose of universities is to foster academic knowledge. Organizational knowledge, on the other hand, is the overall business of the institution, incorporating its strengths and weaknesses, the market it serves, and factors critical to organizational success. However, as Demchig (2015) notes, it seems that higher education institutions are more concerned with knowledge embedded in individuals, and tend to neglect knowledge at the organizational level. Universities should leverage on knowledge assets in individuals by combining knowledge from several sources, co-creating it with other organizations to contribute to the innovativeness of the industry and society as whole (Laine, van der Sijde,

Lähdeniemi, \& Tarkkanen, 2008). Furthermore, as posited by Metcalfe (2006), the academic environment, previously marked by academic capitalism, is shifting toward technocratic decisionmaking, whereby intellectual capital, previously seen as a public good, is now referred to as a 
knowledge asset that can increase institutional legitimacy and provide new revenue streams. In a discourse presented by Metcalfe (2006), she examines the concept of knowledge management in the context of using information technology (IT) for knowledge codification in higher educational settings. She submits that knowledge management is linked to the technological infrastructures of modern organizations. Metcalfe (2006) further argues that the implementation of knowledge management principles in higher education should proceed only with the careful examination of economic, political, and social implications of knowledge codification. This is in order to prevent the likely negative effects of the ensuing knowledge commodification as to whether knowledge assets should have a market value attached or rather be seen as a social good. However, as noted earlier, the implementation of knowledge management in organizations should not focus only on technology, but also on the people and the inherent processes. In fact, universities should not focus on adopting fragmented parts of knowledge management principles, but on the overall principle. For instance, Santos (2006) reports the case of an unsuccessful knowledge management initiative in a university in the United States that focused only on developing the capacity for information systems, but failed to develop capacities in the other critical areas necessary to interpret and create knowledge.

Knowledge management applied to Higher Education Institutions (HEIs) can bring about improvement in processes, such as the research process, curriculum development process, student and alumni services, administrative services, and strategic planning (Kidwell et al., 2000). HEIs can use knowledge management to achieve a more comprehensive, integrative, and reflexive understanding of the impact of information on their institutions (Petrides \& Nguyen, 2006). In the same vein, Bhusry, Ranjan, and Nagar (2011) in their study of HEIs in India, infer that knowledge management interventions have the potential to impact functional domains, such as planning and development, research, placement services, teaching and learning processes, performance evaluation of faculty, administrative services, and student affairs. The researchers offer this position in their proposal of a conceptual framework for implementing knowledge management in HEIs in India. Brewer and Brewer (2010) note that having effective knowledge management strategies within a university can help institutions serve their stakeholders better while simultaneously improving organizational and educational outcomes. In another study, Ramakrishnan and Yasin (2012) interviewed a group of academic staff at a Malaysian university, opining that having a knowledge management system in place could enhance the curriculum review process and thereby improve the quality of curricula and programs. According to Yeh (2011), educational administration can support knowledge management, which in turn supports teaching and learning. Also, knowledge management may help improve organizational processes and strategies, enhance institutional reputation, and promote collaborations and innovations (Marouf \& Agarwal, 2016).

Studies that report practical cases of knowledge management initiatives are scarce. However, some studies have examined information systems implementations as surrogates of knowledge management initiatives. The limitation in this is that knowledge management initiatives are restricted to information technology implementations which may not focus on holistic knowledge management principles. For instance, Chae and Poole (2006) report the implementation of a now aging enterprise information system known as University System-Wide Management Information Systems (USMIS) in the 1990s. This system was implemented in a Land Grant University System in the US and it was basically for financial information reporting. While the paper reports the issues in the systems design and implementation from an historical perspective, it recommends a number of factors to be taken into consideration in the implementation of such systems. These factors are organizational resistance to change, top management commitment, regulations from public constituencies, and diversity of internal constituencies. A paper published by Smith (2006) reports on the implementation of a technology for classroom instruction in a research institution in the US. It was found that while the faculty and students experienced enhanced classroom learning, incongruities in values and beliefs of administrators and faculty were barriers to increased 
use of the technology. Similarly, Slater and Moreton (2007) report the case of implementing a knowledge management strategy in the IT services of a university in the United Kingdom (UK). The strategy involved identifying the practices and beliefs that were prevalent in the department, followed by the development of projects to improve the quality of skills and services within the department with the aim of identifying existing knowledge and creating knowledge (via identification of needs and publishing resources on the staff intranet). Other projects were initiated to cater for knowledge sharing, utilization, and retaining, as well as measurement. Consequently, they came up with a list of guidelines they suggest can improve knowledge management initiatives in universities. These guidelines, thematically are the following: organizational issues; training and staff development; recognition and reward; staff profiling; staff participation; knowledge interviews; project management; customer profiling; measurement; tools and resources; and current awareness (Slater \& Moreton, 2007).

In the Nigerian context, only a few studies have examined the knowledge management processes in place at universities. Uchendu, Osim, and Akuegwu (2012) examined knowledge management and university lecturers' job performance in Cross River State, Nigeria. The above-mentioned researchers studied knowledge management from the angle of knowledge sharing and knowledge mapping which, they suggest, are its two most crucial components. Uchendu et al. (2012) found a significant relationship between knowledge sharing, knowledge mapping, and lecturers' job performance. Ohiorenoya and Eboreime (2014) surveyed knowledge management practices and performance in some Nigerian universities. These researchers measured knowledge management via six components: creation, capturing, organization, storage, dissemination, and application. Indicators of performance, on the other hand, were competitive advantage, innovation, and growth.

Ohiorenoya and Eboreime (2014) found a high positive correlation between knowledge management and performance in Nigerian universities. However, the researchers did not specify the way in which the researchers were able adequately to capture the responses of their participants to the indicators of performance (competitive advantage, innovation, and growth). Also, the findings predispose one to assume that knowledge management (its creation, capturing, organization, storage, dissemination, and application) is fully practiced in the selected universities, without their stating their most common practices. Also, Akuegwu and Nwi-ue (2013), in a survey of the application of knowledge management skills in university administration in Nigeria, found that Heads of Departments (HODs) are effective in their level of application of knowledge sharing and knowledge-capturing in university administration. However, they found HODs to be poor in their application of knowledge mapping and knowledge storage apropos of university administration. Similarly, Krubu and Krub (2011), in their study of Nigerian universities, concluded that knowledge management initiatives are still at their most basic level, and they therefore call for a conscious and deliberate strategy to implement knowledge management initiatives in Nigerian universities.

The preceding points emphasize that knowledge management is a veritable tool that could help HEIs achieve their desired competitive edge and simultaneously improve performance and innovation. However, there is a need to establish a strategy in order to achieve this. Studies within the Nigerian context suggest that there are no conscious strategies in place for applying knowledge management: this calls for the proposed conceptual model.

\section{Conceptual Model for Knowledge Management Practices in Universities}

Given the literature reviewed above, a conceptual model is proposed. This model is an adaptation of Evans et al.'s (2014) integrated knowledge management cycle model and is adopted because of the depth and comprehensiveness which each stage of the knowledge management process exam- 
ines. The proposed model, as shown in Figure 1, consists of five main knowledge management phases: identification, storage, sharing, application, and evaluation.

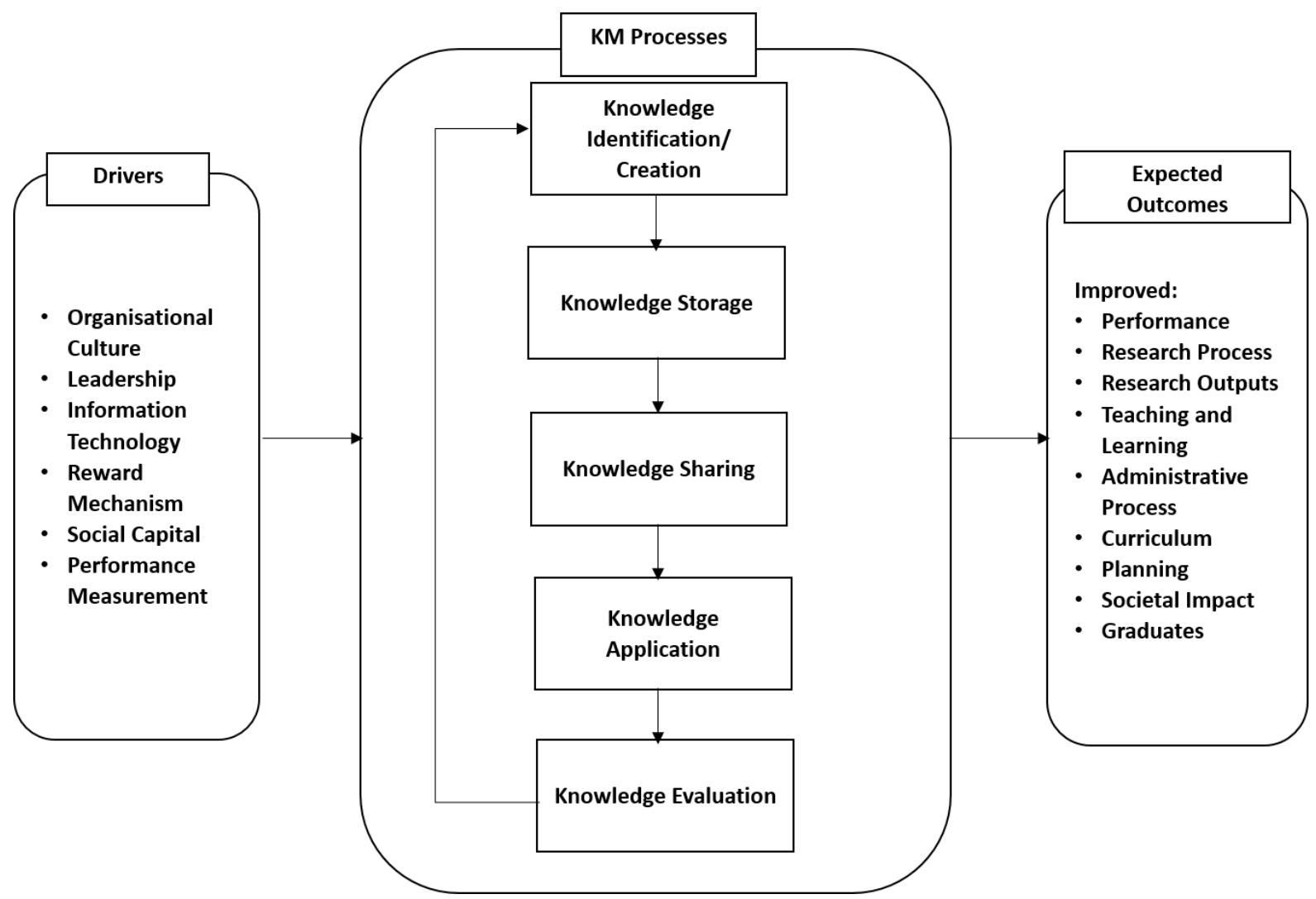

Figure 1: A Conceptual Model for Knowledge Management in Nigerian Universities.

The first stage in the cycle is knowledge identification. At this stage, it is important for an institution to identify its knowledge needs, in order to gather the appropriate knowledge. Knowledge identification is significant for universities intending to leverage their knowledge assets for the purpose of solving problems, planning strategically, developing curricula, and for overall repositioning. Universities are in the knowledge business; as such, they should be able to identify their existing knowledge assets and create new knowledge as the need arises. Knowledge assets in a university comprise the academic knowledge resident in the faculty members and administrative staff. Assets also include organizational knowledge, which is a documentation of the institution's strengths and weaknesses (Yeh, 2011). Knowledge identification is likened to knowledge mapping which involves measuring the intellectual capital available in the institution by way of visualizing knowledge assets in order to recognize how, when and where to access knowledge (Balaid, Abd Rozan, Hikmi, \& Memon, 2016). According to Jones, Meadow, and Sicilia (2009), performing such a process would enable universities to know their core competencies, thereby ensuring better allocation of resources, identifying potential synergies, and attaining their goals. Knowledge identification may be considerably easier with the existence of personnel records outlining the expertise of faculty members which are categorized along the lines of departments and faculties/schools/colleges, as is the case in most Nigerian universities. This is because university lecturers are expected to be experts in their field, with the exception of junior lecturers who are not yet fully au fait. Another means of identifying knowledge, especially for the purpose of encapsulating tacit knowledge, is through network analysis or brainstorming sessions. This can help create knowledge at departmental and faculty level, which can then be integrated into an institution-wide knowledge repository. Also embedded in the identification stage is knowledge creation. 
According to Siadat, Hoveida, Abbaszadeh, and Moghtadaie (2012), knowledge creation is important for universities to achieve their goals of meeting societal needs, at the same time internally improving the quality of education delivered. In their study of an Iranian university, the abovementioned researchers state that social capital and organizational culture are two important facilitators of knowledge creation.

The second stage is knowledge storage. The essence of knowledge identification is to own a knowledge repository which may be consulted as the need arises. Once one has identified and encapsulated knowledge, one must store it in a repository. In a university setting, however, apart from a repository containing subject experts by their specialization, there is a need for a repository of academic and administrative activities. As highlighted by Kidwell et al. (2000), a university should have a repository of research interests, faculty's research outputs, curriculum revision efforts, students' evaluation techniques, and data related to accountability, among others. In summary, a university should have a structured repository of every item of knowledge considered valuable to its existence and performance. This repository could be in the form of corporate portals that are accessible to internal and external stakeholders, as deemed fit.

Knowledge sharing is the third stage. Here, institutions must make an effort to share knowledge that is captured in repositories or resident in individuals. Knowledge sharing is central to knowledge management activities as it is a prelude to knowledge application or use. Studies have in fact shown that having an individualistic culture in universities leads to decreased research output, while a collectivist culture that promotes teamwork positively impacts increased research output (Moss, Kubacki, Hersh, \& Gunn, 2007). The leadership of universities should create a collaborative atmosphere encouraging knowledge sharing among employees. This is particularly important considering the tacit knowledge intrinsic in older faculty members who may leave the institution on retirement. Also, universities should employ technology, such as social media, email messages, text messages, and web portals, to ensure prompt dissemination of knowledge to the various areas of need.

A study of the factors influencing knowledge sharing in a Malaysian university found that having a reward mechanism in place motivated the academics. Also, encouraging academic members to contribute to the university knowledge base with the personal expectation of receiving useful knowledge in return, encouraged staff to share their knowledge (Cheng, Ho, \& Lau, 2011). In addition, a knowledge-sharing culture makes it easy for people to ask what they do not know, thereby boosting faculty morale and contributing to the attainment of institutional goals and objectives (Marouf \& Agarwal, 2016).

Knowledge application is the fourth stage. For benefits to be derived from knowledge management initiatives, institutions must apply the acquired knowledge for the purpose of improving efficiency and innovation. Academic and administrative activities must apply knowledge management to give a university the needed competitive edge. Scholars have highlighted that universities should apply knowledge management for improving teaching, learning, and research processes; establishing new academic programs; reinforcing existing curricula; improving student and alumni services; strategic planning and development; policy formulation; and improving overall service delivery (Bhusry et al., 2011; Brewer \& Brewer, 2010; Kidwell et al., 2000).

The next and final stage is evaluation, which assesses and measures the result of the knowledge application process. Similar to the learn and improve stage posited by Evans et al. (2014), this stage helps to show whether the knowledge applied is of value or whether there is a need for acquiring more knowledge. This final stage, which is a review of the overall knowledge management process, leads back to the identification stage.

This model is proposed for guiding universities in their knowledge management efforts and initiatives. It is important to note, however, that there are a number of factors that serve as enablers or 
drivers for each of the processes highlighted in the model. Importantly, a knowledge management system in a higher education setting should be able to harness the institution's people, processes, technologies, and structure, in promoting best practices, and knowing what works or does not (Dalkir, 2009; Yeh, 2011). Similarly, Petrides and Nguyen (2006) submit that an information sharing culture, reward system, and a culture that supports information-based decision making are key components of successful knowledge management initiatives. Also, Lee and Roth (2009) posit that one may strengthen knowledge management strategies by taking cognizance of four essential domains in the context of higher education. These domains are leadership, culture, technology, and measurement.

Based on the aforementioned premise, it is important for universities to place leaders in positions in which they can champion the knowledge management process and encourage an organizational culture that promotes knowledge sharing, and in which they can harness information technology tools. This is also in line with a study in Malaysian universities that discovered that leadership, culture, information technology, and performance measurement are important enablers of knowledge management implementation (Ramachandran, Chong, \& Wong, 2013). Marouf and Agarwal (2016) suggest that universities should conduct a readiness assessment before embarking on implementing knowledge management initiatives.

The conceptual model put forward in this paper is based on the premise of the gamut of challenges facing Nigeria universities and the need to implement knowledge management initiatives to tackle some of the challenges. Hence, this model can serve as a basis for guiding universities in implementing knowledge management initiatives. It can also serve as a conceptual foundation for future empirical studies which can help understand existing knowledge management practices as well as identify gaps needed for improvements. It can also be used as a basis for understanding the drivers of knowledge management initiatives in universities, as well as for assessing the effects of knowledge management practices on universities' performance.

This paper is not without some limitations. First, it is a conceptual paper that utilized a desk approach in the literature review of existing concepts and models. There could have been an oversight on the part of the author in the studies selected for review. Also, the proposed model is an adaptation of an existing model, but with focus on universities. The scarcity of studies that investigate knowledge management initiatives or practices in the context of Nigerian universities is a limitation worth acknowledging.

\section{Conclusion}

This paper proposes a model for implementing knowledge management initiatives in Nigerian universities. The model adapts Evans et al.'s (2014) integrated knowledge model by way of describing the stages in the context of the operations of a university. It is evident from the foregoing discussion that, for higher education institutions to remain competitive and innovative in the 21st century, knowledge management strategies must be initiated. Universities have a mandate to generate knowledge that is useful for the development of the society in which they are found, while also collaborating with industries. In addition to this, they must turn out graduates who are intellectually competent to tackle the various challenges emerging in the society.

However, universities in Nigeria, as in much of Africa, face challenges that prevent them from achieving their goals and objectives. A knowledge management strategy intentionally set in place could help to overcome some of the challenges faced, thereby driving innovation and growth in Nigerian universities. The model proposed in this study could be extended to other African and developing countries; however, it must be subjected to an empirical test for validation and improvement. Further studies may focus on factors that can influence each stage of knowledge management in the context of Nigerian universities as well as in other universities in Africa. 


\section{References}

Abell, A., \& Oxbrow, N. (2006). Competing with knowledge. London: Facet Publishing.

Adhikari, D. R. (2010). Knowledge management in academic institutions. International Journal of Educational Management, 24(2), 94-104.

Akinrinade, S. (2013). Challenges and innovation in higher education management in Nigeria: Reflections \& lessons in the light of recent experience. In Presentation at the 2nd FUNAI Leadership Development Seminar.

Akinyemi, S., \& Bassey, O. I. (2012). Planning and funding of higher education in Nigeria: The challenges. International Education Studies, 5(4), 86-95.

Akuegwu, B. A., \& Nwi-ue, F. D. (2013). Application of knowledge management skills in university administration in Nigeria : Evidence from heads of departments. British Journal of Education, Society \& Behavioural Science, 3(4), 574-588.

Balaid, A., Abd Rozan, M. Z., Hikmi, S. N., \& Memon, J. (2016). Knowledge maps: A systematic literature review and directions for future research. International Journal of Information Management, 36(3), $451-475$.

Bhatt, G. D. (2001). Knowledge management in organizations: Examining the interaction between technologies, techniques, and people. Journal of Knowledge Management, 5(1), 68-75.

Bhusry, M., Ranjan, J., \& Nagar, R. (2011). Implementing knowledge management in higher educational institutions in India: A conceptual framework. International Journal of Computer Applications, 29(1), $34-46$.

Brennan, J., King, R., \& Lebeau, Y. (2004). The role of universities in the transformation of societies. An International Research Project. London.

Brewer, P. D., \& Brewer, K. L. (2010). Knowledge management, human resource management, and higher education: A theoretical model. The Journal of Education for Business, 85, 330-335.

Bukowitz, W., \& Williams, R. (2000). The knowledge management fieldbook. London: Prentice Hall.

Carneiro, A. (2000). How does knowledge management influence innovation and competitiveness? Journal of Knowledge Management, 4(2), 87-98.

Chae, B., \& Poole, M. S. (2006). Enterprise system development in higher education. In A. S. Metcalfe (Ed.), Knowledge management and higher education : A critical analysis (pp. 196-221). Hershey, PA: Information Science Publishing.

Chen, I.-S., Chen, J.-K., \& Padró, F. F. (2015). Critical quality indicators of higher education. Total Quality Management \& Business Excellence, 1-17.

Cheng, M., Ho, J. S., \& Lau, P. M. (2011). Knowledge sharing in academic institutions : A study of Multimedia University Malaysia. Electronic Journal of Knowledge Management, 7(3), 313-324.

Cranfield, D. J., \& Taylor, J. (2008). Knowledge management and higher education : A UK case study. The Electronic Journal of Knowledge Management, 6(2), 85-100.

Dalkir, K. (2009). Knowledge management. In Encyclopedia of Library and Information Sciences (3rd ed., pp. 3129-3138). New York: Taylor and Francis.

Demchig, B. (2015). Knowledge management capability level assessment of the higher education institutions : Case study from Mongolia. Procedia - Social and Behavioral Sciences, 174, 3633-3640.

Echeng, R., Usoro, A., \& Majewski, G. (2013). Acceptance of Web 2.0 in learning in higher education : A case study Nigeria. (IJACSA) International Journal of Advanced Computer Science and Applications, $4(10), 146-151$. 
Evans, M., Dalkir, K., \& Bidian, C. (2014). A holistic view of the knowledge life cycle: The Knowledge Management Cycle (KMC) Model. The Electronic Journal of Knowledge Management, 12(2), 148160.

Ezepue, P. O. (2015). Ezepue lists bane of higher education in Nigeria. Retrieved July 30, 2015, from http://www.unilorin.edu.ng/index.php/en/2013-09-02-10-18-35/news-feed/4481-ezepue-lists-bane-ofhigher-education-in-nigeria

Famurewa, I. O. (2014). Inadequate funding as the bane of tertiary education in Nigeria. Greener Journal of Economics and Accountancy, 3(2), 20-25.

Fullwood, R., Rowley, J., \& Delbridge, R. (2013). Knowledge sharing amongst academics in UK universities. Journal of Knowledge Management, 17(1), 123-136.

Jones, N., Meadow, C., \& Sicilia, M.-A. (2009). Measuring intellectual capital in higher education. Journal of Information and Knowledge Management, 8(2), 113-136.

Kidwell, J. J., Vander Linde, K., \& Johnson, S. L. (2000). Applying corporate knowledge management practices in higher education. Educause Quarterly, 4, 28-33.

Krubu, D. E., \& Krub, S. G. (2011). Towards sustainable development: An assessment of knowledge management initiatives in Nigerian universities. Journal of Sustainable Development in Africa, 13(3), 165177.

Laine, K., van der Sijde, P., Lähdeniemi, M., \& Tarkkanen, J. (Eds.) (2008). Higher education institutions and innovation in the knowledge society. Helsinki: Publisher Rectors' Conference of Finnish Universities of Applied Sciences.

Lee, H., \& Roth, G. L. (2009). A conceptual framework for examining knowledge management in higher education context. New Horizons in Adult Education and Human Resource Development, 23(4), 22 37.

Marouf, L. N., \& Agarwal, N. K. (2016). Are faculty members ready? Individual factors affecting knowledge management readiness in universities. Journal of Information \& Knowledge Management, 15(3), 1650024.

Metcalfe, A. S. (2006). The political economy of knowledge management in higher education. In A. S. Metcalfe (Ed.), Knowledge management and higher education : A critical analysis (pp. 1-20). Hershey, PA: Information Science Publishing.

Moss, G., Kubacki, K., Hersh, M., \& Gunn, R. O. D. (2007). Knowledge management in higher education: A comparison of individualistic and collectivist cultures. European Journal of Education, 42(3), 377394.

Nonaka, I. (1994). A dynamic theory of organization knowledge creation. Organization Science, 5(1), 14 37.

NUC. (2016a). About us. National Universities Commission. Retrieved from http://nuc.edu.ng/about-us/

NUC. (2016b). Federal universities. National Universities Commission. Retrieved from http://nuc.edu.ng/nigerian-univerisities/federal-univeristies/

Ohiorenoya, J. O., \& Eboreime, O. F. (2014). Knowledge management practices and performance in Nigerian universities. European Scientific Journal, 10(16), 400-416.

Ololube, N. P., Dudafa, U. J., Uriah, O. A., \& Agbor, C. N. (2013). Education for development: Impediments to the globalization of higher education in Nigeria. International Journal of Educational Foundations \& Management, 1(2), 109-130.

Omerzel, D. G., Biloslavo, R., \& Trnavčevič, A. (2011). Knowledge management and organisational culture in higher education institutions. Journal for East European Management Studies, 16(2), 111-139. 
Petrides, L. A., \& Nguyen, L. (2006). Knowledge management trends: Challenges and opportunities for educational institutions. In A. S. Metcalfe (Ed.), Knowledge management and higher education: A critical analysis (pp. 21-33). Hershey, PA: Information Science Publishing.

Plessis, M. Du. (2007). The role of knowledge management in innovation. Journal of Knowledge Management, 11(4), 20-29.

Ramachandran, S. D., Chong, S.-C., \& Wong, K.-Y. (2013). Knowledge management practices and enablers in public universities: A gap analysis. Campus-Wide Information Systems, 30(2), 76-94.

Ramakrishnan, K., \& Yasin, N. (2012). Knowledge management system and higher education institutions. In International Conference on Information and Network Technology (Vol. 37, pp. 67-71).

Rastogi, P. N. (2000). Knowledge management and intellectual capital - The new virtuous reality of competitiveness. Human Systems Management, 19(1), 39-48.

Rowley, J. (2000). Is higher education ready for knowledge management? The International Journal of Educational Management, 14(7), 325-333.

Ruggles, R., \& Holtshouse, D. (1999). The knowledge advantage. New Hampshire: Capstone Publisher.

Santos, J. L. (2006). Institutional research (IR) meets knowledge management (KM). In A. S. Metcalfe (Ed.), Knowledge management and higher education : A critical analysis (pp. 93-113). Hershey, PA: Information Science Publishing.

Siadat, S. A., Hoveida, R., Abbaszadeh, M., \& Moghtadaie, L. (2012). Knowledge creation in universities and some related factors. Journal of Management Development, 31(8), 845-872.

Slater, A., \& Moreton, R. (2007). Knowledge management in higher education: A case study in a large modern UK university. In M. Gabor, K. Gabor, W. Wojtkowski, W. G. Wojtkowski, \& J. Zupančič (Eds.), Advances in information systems development: New methods and practice for the networked society (2nd ed., pp. 371-382). New York: Springer.

Smith, K. M. (2006). Higher education culture and the diffusion of technology in classroom instruction. In A. S. Metcalfe (Ed.), Knowledge management and higher education : A critical analysis (pp. 222241). Hershey, PA: Information Science Publishing.

Sunassee, N. N., \& Sewry, D. A. (2002). A theoretical framework for knowledge management implementation. In Proceedings of SAICSIT 2002 (pp. 235-245).

Times Higher Education. (2016). World university rankings 2016-2017. Retrieved from https://www.timeshighereducation.com/world-university-rankings/2017/worldranking\#!/page/0/length/25/sort by/rank label/sort order/asc/cols/rank only

Uchendu, C., Osim, R., \& Akuegwu, B. (2012). Knowledge management and university lecturers' job performance in Cross River State, Nigeria. Journal of Education and Practice, 3(15), 1-6.

White, S. C., \& Glickman, T. S. (2007). Innovation in higher education: Implications for the future. New Directions for Higher Education, 2007(137), 97-105.

Wiig, K. M. (1993). Knowledge management foundations: Thinking about-how people and organizations create, represent, and use knowledge. Arlington, TX: Schema Press.

Yeh, Y. (2011). The implementation of knowledge management system in Taiwan's higher education. Journal of College Teaching \& Learning (TLC), 2(9), 35-42. 


\section{Biography}

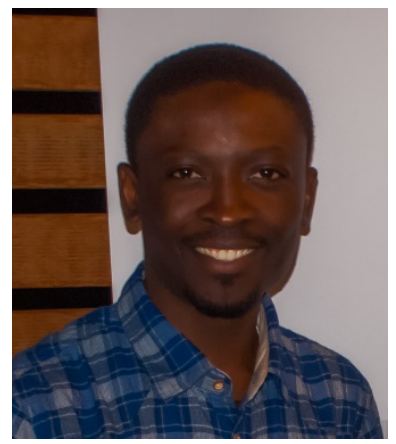

Adebowale Ojo is a Postdoctoral Research Fellow in the Discipline of Information Systems \& Technology, School of Management, IT \& Governance at the University of KwaZulu-Natal, South Africa. He obtained his doctorate in Information Resources Management from Babcock University, Nigeria. His research interests include health informatics, knowledge management, mobile technologies, and ICT for Development. He is a member of the Association for Information Systems (AIS) and the Institute of Information Technology Professionals of South Africa (IITPSA). 